\title{
Open Badges: A Best-Practice Framework
}

\author{
Lennert Voogt, Lisa Dow, Simon Dobson \\ School of Computer Science \\ University of St Andrews \\ St Andrews, UK \\ lav2@st-andrews.ac.uk
}

\begin{abstract}
The widespread adoption of online education is severely challenged by issues of verifiability, reliability, security and credibility. Open Badges exist to address these challenges, but there is no consensus as to what constitutes best practices regarding the implementation of an Open Badge system within an educational context. In this paper we survey the current landscape of Open Badges from educational and technological perspectives. We analyze a broad set of openly-reported pilot projects and case studies, and derive a comprehensive best practice framework that tries to capture the requirements for successful implementation within educational institutions. We conclude by identifying some significant gaps in the technology and identify some possible future research directions.
\end{abstract}

\section{Keywords-Open Badges, Online Education, Framework,} Credentialing

\section{INTRODUCTION}

Mozilla's Open Badges project was launched in 2012. Open Badges are essentially digital image files [1] that can be earned both online and offline. The badges contain metadata that indicate the learner's achievements and provide information about the issuing institution. Badges are generally created, issued and managed through an open-source system, called the Open Badge Infrastructure [2]. The main motivation behind their development was to create a system with enhanced interoperability and thereby improve upon what academics have labeled as the most prominent limitations of existing sources of online education and MOOCs, namely: "credibility, accessibility, the high demand for motivation and self-regulation" [3], as well as trust and safety issues [4].

While adoption has increased steadily, Open Badges themselves do not present a perfect solution. Common criticisms highlighted by academics include: the theory of "motivation displacement" whereby students "are engaged in a task for its own sake" [5] and the fact that badges can be issued by anyone, which "raises concerns about their credibility and reliability" [6]. In addition, while Mozilla promotes the idea of compatibility across institutions, the "sharing of badges is [still] not frictionless" [7]. Research on the effectiveness of implemented Open Badge systems is also in its infancy and has been hampered by the speed with which technical specifications are updated and the varying needs of the stakeholders involved.

This paper therefore begins by providing a topical overview of the current literature by detailing the motivations behind the creation of Open Badges, before highlighting the main benefits and limitations of the system. We then survey the current landscape of Open Badges within an educational context and explore the underlying technology, before analyzing the main technologies being developed in the field. We then develop a comprehensive best practice framework by critically analyzing case studies and pilot projects that have been conducted worldwide. We conclude by assessing the proposed framework and by suggesting future research directions.

\section{BACKGROUND AND MOTIVATION}

Open Badges have been hailed as a significant advance for educators, with [8] stating they have improved on multiple issues hampering online education. These benefits range from positive effects on student motivation [9] and increased mobility and portability [10], to reduced overall costs of education and a subsequent increase in access to a wider audience [11].

One of the main drivers of adoption for MOOCs, and Open Badges by extension has been the increasing cost of oncampus education worldwide, which has put universities and other educational institutions under pressure to offer alternatives, such as online courses [12]. As a result of these rising costs, students have begun to question the value of traditional sources of knowledge and education, causing the online education movement to gain "significant momentum" [13]. Open Badges is a particularly intriguing response to this problem, as issuing online badges can provide a "way to help deliver 'low-cost' or more cost-effective assessment" [14]. The general sentiment is summarized by stating that: "skills or expertise is going to move from the certificate or degree to the badge" [29]. 
In addition to the increasing costs of education, the last decade has seen employers demand increasingly varied proficiencies referred to as " 21 st Century Skills" [15]. It has been argued that Open Badges have emerged in part because they "neatly meet [these] ever-increasing workplace demands" [16], which affects both job-seekers and employees. Indeed, changing workplace demands have stimulated the adoption of Open Badges because, "skills developed in one job, for example, can be displayed to subsequent employers" [17]. This portability is especially beneficial for users as the Open Badging system allows for rapid validation with employers and skills can be displayed on a variety of mediums ranging from "jobs profiles [to] social networking sites" [15].

Furthermore, a study for the Harvard Business Review found that while universities fear that online education will "cannibalize their business model", it can instead allow for a diversification of revenue and is therefore "more like an opportunity" [18]. Indeed, it can be argued that Open Badges will "provide new possibilities for revenue, as well" [19].

Despite increasing adoption and usage, however, critics have pointed to many "practical and theoretical objections" [20] relating to digital badges in general and Open Badges by extension. Common criticisms include; the lack of clarity regarding "the meaning of badges" [21], digital badges' role in the commodification of learning [22], the theory of motivation displacement [23] and recurring concerns regarding credibility, reliability [6], mobility [7] and privacy [24].

While online education is gaining in popularity across the globe, one major barrier to widespread adoption is the preconceived notions and prejudice against the idea of online education and the administering of Open Badges [12]. The "use of badges in formal education is a conceptual struggle" that must first be overcome in order to popularize Open Badges worldwide [24]. Indeed, Cathy Davidson, a co-founder of HASTAC, an organization that is a strong proponent of Open Badges, has previously claimed that her "biggest hurdle ... was prejudice" [25].

This largely derives from the fact that Open Badges are seen as "disruptive" [26]. In addition to the tendency for online courses to be free due to the marginal cost of production [27], institutional resistance to the idea of Open Badges also stems from the fact that Open Badges "challenge the credentialing authority of higher education" [16]. It has been argued that Open Badges can reform "higher education through alternative assessment for students" [62]. Educational institutions are also hesitant to implement Open Badges as they believe that online courses simply cannot match oncampus programmes [12].

Importantly for issuing institutions, credibility is one of the largest issues hampering adoption of Open Badges, and MOOCs in general [1]. Ultimately, the desirability of Open Badges rely on the value that other stakeholders, such as employers and professional bodies, place on them, in addition to the badge taker [29].

However, while [21] does acknowledge that Open Badges provide greater credibility than MOOCs and can in certain cases lead to improved credibility and trust [31], these criticisms have served as a foundation for the prejudice and inertia from students and teachers that restricts the introduction of Open Badge courses within an educational context. Ultimately, this can result in hesitancy with "commit[ing] [the] resources" [28] needed to implement an Open Badge system.

Perhaps most critically for institutions, the absence of a consensus regarding implementation of an Open Badge system in educational contexts has also hampered adoption rates. This is largely due to the infancy of the academic research on implementation and the speed with which the Open Badge system and underlying technological components change.

\section{TECHNOLOGY}

The technology needed to create, issue, manage and support Open Badges include core components such as the badges themselves, a structure such as the Open Badge Infrastructure and the active participation of the appropriate stakeholders, which include issuers, users, displayers, endorsers and consumers.

Badges are the "core currency of exchange" and the method with which a credential can demonstrate a "skill, achievement, quality or affiliation" [33]. Due to the open source nature of Open Badges, it is the responsibility of the issuer to determine what precisely their Open Badge will credential. Essentially, badges are .PNG image files [32], which in order to fulfill Mozilla's requirements, are "baked in" the JSON format with its underlying metadata. This process of 'baking', otherwise called asserting, is the process of linking the "badge back to the issuer" [32]. The metadata within a badge itself is referred to as the 'Badge Manifest', which shows "user identify information (email address) plus badge information (JSON metadata)". More precisely, [32] specifies that the manifest contains "data .. about the issuer, the earner, and the circumstance about how it was earned".

As the badge is then forever linked to its assertion after 'baking', "there's very little within a badge that can be tampered with, and validation of the badge can be achieved by quickly and simply reading the information held in the assertion" [34]. The author further states that these assertions are encrypted, or "hashed using SHA". It has also been suggested that the presence of the "Criteria URL and the Evidence URL" ensures there is complete transparency in what specifically was achieved in order to be awarded a particular badge [35]. However, a badge can also remain 
unverified, if the assertion is not made or is deemed unnecessary by the issuer. Badges themselves are entirely individual and unique, and in most cases relate directly back to a specific issuing body.

\section{Level 2 on Fundamentals of Design}

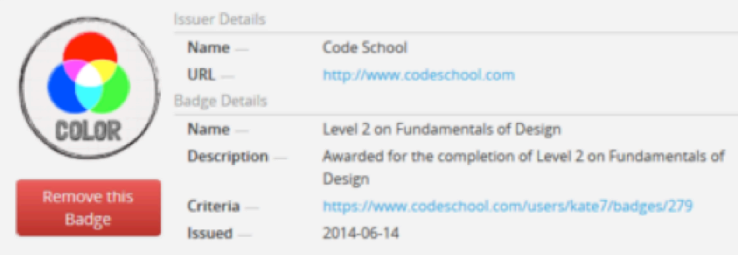

Fig. 1. Example Open Badge with underlying Metadata [63]

Fig. 1, for example, shows a 'Level 2 Fundamentals of Design' badge earned at the University of British Columbia. The underlying assertion is that the earner has completed the course and the badge has been awarded. The metadata specifies: the name of the organization, name of the course, a description of the course, and the issue date.

In addition to badges themselves, the Open Badge Infrastructure $(\mathrm{OBI})$ is the "technical infrastructure that supports open badges systems" [36]. While several institutions have built similar infrastructures [37],[6], these all derive from the OBI and are therefore considered OBI-compliant. The OBI is open-source by design, allowing anyone to develop and issue badges [21] and is used for "issuing and managing digital badges with embedded metadata" [26]. This is made possible by the underlying technology whose "two aspects [are]: (i) the Open Badge [Infrastructure] specification .... and (ii) a Badge Backpack, which is a service that provides badge earners a way to collect and manage badges" [38].

The Mozilla Backpack, or "credential portfolio ... allows a learner to aggregate credentials from a variety of sources" and "store them in a digital backpack" [39], and is hosted by Mozilla. With permission from it's owner, the Mozilla Backpack can be accessed by displayers, such as websites. Alternatively, badges can be displayed on LinkedIn or WordPress via special plug-ins [40].

Finally, in addition to the OBI and badges, the Open Badge system requires the active participation of the individual users, issuers, displayers, and endorsers of badges, as well as the consumers. Users can be defined as "a person storing their badges within the Open Badge Infrastructure" [41]. This person can, for example, attain certain badges, manage them via the Backpack and freely display them across platforms. Secondly, issuers refer to those organizations, institutions or individuals who issue badges in the OBI. Equally as important are the displayers of Open Badges, which are websites that collects the badges from the OBI and allows them to be displayed.

In addition, endorsers are organizations, institutions or individuals that "validate a badge by signing it with their private encryption key" [41]. These signing authorities, for example, are third parties that validate the badges by checking its public encryption key. Lastly, consumers are a key stakeholder. These are the parties that are viewing a user's Open Badges in order to verify a certain skill. These interested parties may be employers, for example [42].

Fig. 2, provides an accurate overview of the entire Open Badge Infrastructure and interactions between the key stakeholders and the underlying technology.

Despite the presence of several limitations, such as the inability to credential soft skills and the possibility of 'motivation displacement', it can be argued that Open Badges have improved on multiple issues hampering online education in general. Therefore, gaining a deeper understanding of Open Badges and the underlying technology allows for a clearer assessment of the system's capabilities, limitations and application for issuing institutions. Most importantly, it provides issuers with a strong technical and theoretical foundation with which they can implement our proposed framework.



Fig. 2. Overview of the Open Badge Infrastructure [64]

\section{METHODS}

The primary aim of this paper is to conduct research on empirical examples of educational institutions that have 
attempted to implement an Open Badge system. This research will form the basis of a best practice framework, which will provide a topical guide on how institutions can practically create, issue, and manage an Open Badge system in an educational context.

A comprehensive framework is developed by systematically analyzing the pilot projects and case studies, and also by comparing and contrasting this with previous attempts at prescriptive frameworks highlighted in Table 2. Lastly, a critical appraisal will be conducted that will highlight possible future directions of Open Badges by identifying gaps in the existing technology and potential barriers to adoption that should be addressed.

A qualitative approach was chosen due the infancy of the academic research on the effectiveness of Open Badges and their underlying frameworks in general. This is reflected in the fact that the majority of the chosen studies are either exploratory or descriptive in nature. Indeed, many institutions are currently trialing an Open Badge system within their respective educational contexts in the hope of determining future improvements to the system. A qualitative approach was also chosen because the methods, goals, size and philosophies of the studies vary widely, which, in the analysis of qualitative pilot studies, should be "mainly descriptive" [48]. A similar approach can be taken towards the case studies that were chosen [43].

Several trends were identified based on the analysis of the chosen pilot projects and case studies and are later integrated into the framework. Firstly, the stated objectives of the studies ranged widely. Due to the infancy of the academic research, several academics conducted exploratory pilot studies [55], [58],[15],[57], which mainly aim to assess feasibility [58] and cost. It can generally be argued that conducting these exploratory studies raise questions "for further research on open badges in higher education" [8].

More recent case studies have attempted to assess the effectiveness of implemented Open Badge systems themselves [37],[50],[9]. In doing so, the researchers aim to further improve the implemented system in order to realize its full potential [9]. Due to the qualitative and exploratory nature of the systems, several studies that have relatively small datasets, with institutions deliberately restricting the size of the study, with a view to later rolling out the system across the rest of the institution [52]. These case studies often conclude by suggesting areas for improvement and future research directions.

While a common criticism of the literature regarding online education in general and Open Badges in particular has been that it is primarily US-centric, the chosen pilot projects and case studies were conducted around the world. Indeed, only 3 out of the $17(17.65 \%)$ cases were explicitly conducted in the United States. More surprisingly, 11 out of the 17 cases
(64.7\%) were conducted by academics focusing on Europe. It can be argued, however, that there is a notable absence of emerging economic regions, such as Asia and Africa. This may in part be due to the 'digital divide' [54] that still permeates the online education industry.

The sample sizes used in both the pilot projects and case studies also varied widely, ranging from 32 potential users [6] to 755 [51]. This is primarily due to the differing approaches taken in measuring the feedback of the participants and relevant stakeholders. In many cases [58],[49],[50],[57],[29],[53],[26],[9],[56], figures regarding the amount of participants were not released. A systematic analysis of the cases also highlighted that a wide range of participants were involved, from teachers and researchers to students.

\section{FRAMEWORK}

The framework was developed by surveying the current literature and systemically analyzing previous pilot and case studies in order to determine an industry 'best-practice' for educational institutions. It was based on the findings relating to Table 1 and Table 2 and references the relevant studies by using the reference codes given to them in the first column. The previous frameworks (in Table 2) are abbreviated, whereas the cases (in Table 1) are labeled based on their stated goal. E1, for example, refers to [55] exploratory study. Similarly, D4 refers to [49] descriptive study.

TABLE I. SUMMARY OF CASE STUDIES AND PILOT PROJECTS

\begin{tabular}{|c|c|c|c|}
\hline \multirow{2}{*}{ Reference } & \multicolumn{3}{|c|}{ Summary of Case Studies and Pilot Projects } \\
\hline & Institution & Author(s) & Year \\
\hline D1 & $\begin{array}{l}\text { Brigham Young } \\
\text { University }\end{array}$ & Randall et al. & 2013 \\
\hline D2 & University of Aveiro & Santos et al. & 2013 \\
\hline D3 & KU Leuven & Charleer et al. & 2014 \\
\hline D4 & $\begin{array}{l}\text { National Research } \\
\text { Council of Italy }\end{array}$ & Cucchiara et al. & 2014 \\
\hline D5 & Open University & Law et al. & 2014 \\
\hline D6 & Peer 2 Peer University & Pogorelc & 2014 \\
\hline D7 & K-12 School System & $\begin{array}{c}\text { Gamrat, } \\
\text { Zimmerman }\end{array}$ & 2015 \\
\hline D8 & MOUSE & O’Bryne et al. & 2015 \\
\hline D9 & Hive Toronto & Smith et al. & 2015 \\
\hline E1 & National 4-H Council & Barker & 2013 \\
\hline E2 & Border College & Scott & 2013 \\
\hline E3 & University of Sussex & Hole & 2014 \\
\hline E4 & $\begin{array}{l}\text { Australian National } \\
\text { University }\end{array}$ & Mewburn et al. & 2014 \\
\hline E5 & Kokkola University & $\begin{array}{c}\text { Myllymaki, } \\
\text { Hakala }\end{array}$ & 2014 \\
\hline E6 & Tallinn University & Poldoja, Laanpere & 2014 \\
\hline E7 & Jorum & Boyle et al. & 2015 \\
\hline E8 & $\begin{array}{l}\text { GRASS, European } \\
\text { Union }\end{array}$ & Devedzic et al. & 2015 \\
\hline
\end{tabular}


TABLE 2. SUMMARY OF PREVIOUS FRAMEWORKS

\begin{tabular}{|l|l|c|c|}
\hline \multirow{2}{*}{ Reference } & \multicolumn{3}{|c|}{ Summary of Previous Frameworks } \\
\cline { 2 - 4 } & \multicolumn{1}{|c|}{ Institution } & Author(s) & Year \\
\hline BA & Badge Alliance & Casili et al. & 2014 \\
\hline DPD & $\begin{array}{l}\text { Design Principles } \\
\text { Documentation Project }\end{array}$ & Hickey et al. & 2014 \\
\hline AEA & $\begin{array}{l}\text { American Evaluation } \\
\text { Association }\end{array}$ & Davies et al. & 2015 \\
\hline UB & University of Belgrade & $\begin{array}{c}\text { Devedzic, } \\
\text { Jovanovic }\end{array}$ & 2015 \\
\hline
\end{tabular}

While there have been numerous attempts at developing a framework [59],[62],[5],[61], this framework is more comprehensive, due to the inclusion of pilot projects, case studies and previous frameworks. It takes a purely institutional perspective as "OB system development is typically initiated by one or more educators" [5]. It was also developed to be as generic and replicable as possible, as "there is no one right way to use badges" [61].

The framework itself can be separated into two distinct sections: Conceptualization; Design and Implementation and is summarized in Fig. 3.

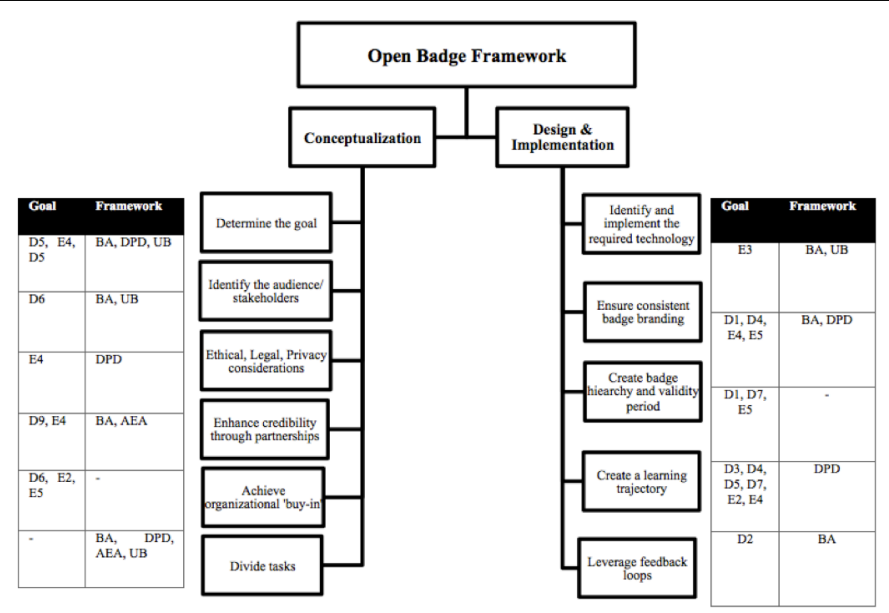

Fig. 3. Overview of the proposed Open Badge Framework

\section{A. Conceptualization}

Fig. 4 shows the process whereby institutions can accurately conceptualize the design of their Open Badge system. These steps will now be further expanded upon and have been supplemented with relevant literature outside of the aforementioned frameworks and cases presented in Tables 1 and 2 .

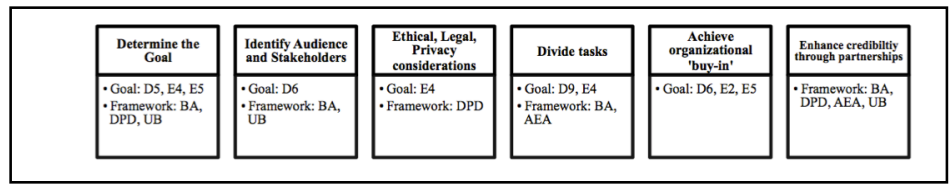

Fig. 4. Considerations for Conceptualization of an OB system

\section{Determine the goal}

The case studies and pilot projects highlight a multitude of goals that institutions have determined from the outset. These range from using an $\mathrm{OB}$ system to: provide acknowledgement and progress of achievements [50],[8],[9], improve student interaction and engagement [9][56], make "education marketing more effective" [29], or simply "making [a] research degree study easier to navigate" [57]. In addition, Open Badges have broad potential educational use, such as in K-12 schools [52] or universities [24] as well as other associations [62].

Indeed, [5] references the "purpose/objectives of the OB system" as an important and crucial part of a preparatory design. Similarly, [44] states that it is "important that the intended function of the badge understood" as it is crucial to "help to build a strong and robust system" [61]. Ultimately, determining the goal greatly influences the scope and direction of the OB system. This could, for example, be achieved by looking at the role badges will play within the institution and what skills they would recognize [59].

\section{Identify the target audience and key stakeholders}

It is also crucial that the target audience and subsequent stakeholders are specifically defined as "different stakeholders have different interests in badges" [5]. This is due to the fact that badge takers may range from university students looking to satisfy their curiosity [45], to those life-long learners taking evening or non-degree courses in search of employable skills [29].

By accurately identifying the target audience and stakeholders, educational institutions can better meet the expectations of its users and potentially provide an enticing "value proposition" [5]. For example, [51] conducted a pilot study at the Peer 2 Peer University. By "building small pilots and testing them... early and valuable feedback" was received, which led to the "unexpected" realization that the "main beneficiaries ... [were] informal learning organizers" instead of a wider audience [51]. This feedback allowed the university to adjust its product offering. More specifically, pilot projects or surveys can be conducted, which could allow 
issuing institutions to determine who their primary and secondary users will be [59].

\section{Consider the ethical, legal and privacy implications}

It has been argued that: "as badges operate in the realms of new forms of learning recognition... it's essential to keep in mind their ethical and legal considerations" [61]. These concerns have arisen due to the fact that there is a "complete disjuncture between legal/policy frameworks and realities of $21^{\text {st }}$ century technology and needs" [57] and there is "no detailed ethical framework has been developed" [46].

More concretely, a pilot study at the Australian National University highlighted the importance of developing an "ethico-legal" framework, which could "be applied to the issuing of the badge" [57]. More generally, it is important for institutions to develop a tailored ethical and legal framework that takes into account the needs and locations of all the stakeholders. This can most effectively be achieved by involving the necessary stakeholders and discussing the "tensions between practices" [61].

\section{Effectively divide tasks for implementation}

The necessity for extensive collaboration to develop "badge concepts and activities" [54] is important as the development team may "be comprised of a number of individuals" [59]. This is due to the tendency for educational institutions to have a variety of academic, legal and practical design considerations to take into account.

Institutions should therefore collaborate effectively in order avoid what can be classified as "death by committee" [57]. More importantly, institutions need to pay particular attention to "who should play a role" in this development, and how tasks should be divided in order to create an effective implementation plan. It has been suggested that this can be realized through creating a "division of labor model" which "makes the system less cumbersome" [62]. It is further stated this could be achieved through altering the OB system on an organizational level, but also by allowing much of the work to "be done by authorized badge issuers".

\section{Achieve organizational 'buy-in' from the outset}

The process of implementing an OB system in an educational context can be construed as disruptive and therefore be met with resistance [20]. Indeed, "certain [institutional] practices are firmly entrenched and changing them may be difficult" [59]. According to academics, one effective method of overcoming institutional inertia to badging [47] is by achieving organizational "buy-in" [56].

Indeed, a recent pilot study for JISC RSC Scotland at Borders College suffered precisely due to the lack of support from the relevant stakeholders [56]. It was concluded that with "full buy-in from the outset it would have been easier to introduce the concept" of Open Badging. More specifically, this can be achieved through involving individuals in focus groups to "gather suggestions ... [and] prioritise" [29]. Furthermore, it was discovered that "instructors, organizers or facilitators quite often needed to buy in" to the idea of OB's, which can be achieved through involving all necessary stakeholders and altering the system to most effectively reflect the needs of it's potential users [51].

By achieving organizational buy-in, institutions can in turn ensure effective implementation by clearly and enthusiastically communicating the benefits of the systems to prospective students and users [30].

\section{Enhance credibility through partnerships}

As has accurately been pointed out: "the value of a badge is determined by the significance" that is attached to it by the earner, issuers and viewer of the badge [29]. Badge earners ultimately display badges to portray certain skills and competencies that are employable. Therefore, in order to stimulate students to earn and display badges, credibility and external trust must be developed [59].

It is suggested that this can be accomplished by communicating the "value proposition" to "parents, associations of educators, employers" amongst other stakeholders [5]. Indeed, [61] similarly argue that "external backing" can be attained through creating formal relationships, which can increase the badges "external value". Creating these formal relationships allow badge viewers to become familiar with both the idea of badges and the issuing institution. If the issuing institution is well respected, this will exponentially increase the value of the badge and thereby further motivate students to earn additional badges.

The six aforementioned steps allow institutions intent on developing an Open Badge system to accurately conceptualize a potential design. Conceptualization is a critical first step in the development of an Open Badge system as it allows the issuing institution to determine their value proposition to badge takers, highlight the goals of the system, determine constraining factors and create a foundation for effective and successful implementation. While the steps should ideally be addressed sequentially, from accurately determining a goal to enhancing credibility through partnerships, several are overlapping in nature and may therefore require varying amounts of time and attention. Upon completion, institutions should begin considering design aspects before actual implementation. 


\section{B. Design and Implementation}

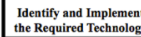

-Goal: E3

- Framework: BA, UB

\section{\begin{tabular}{c}
$\begin{array}{c}\text { Consistent badge } \\
\text { branding }\end{array}$ \\
\hline
\end{tabular} \\ Framework: BA, DPD}
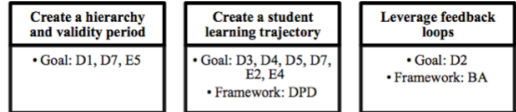

Fig. 5. Considerations for Design and Implementation

\section{Identify and implement the required technology}

The most important starting point in the development phase is accurately determining the technology that will be used [59]. This greatly depends on the scope of the project, the resources that are available, and the existing infrastructure within the institution.

Initially, institutions should familiarize themselves with the existing "badge design tools and badge issuing platforms" [5]. This is especially important and may differ on a case-to-case basis due to the rapidly developing options and technical specifications [6]. Popular solutions include the Mozilla Badgekit and BadgeOS for design, issuing and displaying badges [58],[49]. Mozilla Backpack [42],[1],[2], for example, is the "most widely used OBI-compliant backpack" [5] for storage.

\section{Ensure consistent badge branding}

Creating a visually appealing badge brand identity for the institution is also important [59],[29],[26] as it can "foster brand loyalty and customer retention" [42] and serve as a "method of promoting their brand" [24]. It has even been stated that design and branding have "direct consequences" on motivation as well [61].

Indeed, [57] describe that a key finding upon interviewing students that participated in their pilot study was that they wanted the badges to "look official" and "represent the ANU [Australian National University] brand". A further analysis of the findings in the chosen pilot projects and case studies indicates that one method with which this can be accomplished is through consistent design of the badges that are issued. This is referred to as designing in a "commonbased way" [49], and is echoed by [26], which found that creating standardized rubrics led to their badges having "consistency and rigor".

\section{Implement effective design principles}

Academics have also highlighted that the Open Badge Infrastructure benefits from the ability "to set an expiration date for a badge" [26]. It is argued that it is a "useful feature", because it ensures that skills remain relevant [29].
In addition to a time period, many of the case and pilot studies [26], documented the use of a hierarchical badge structure [14]. This refers to the practice of providing "different levels of badges" which display various skills from "basic or foundational.... to expert" [31]. Practioners recommend the creation of a badging hierarchy because it allows learner to "decide their level of assessment" [52]. In other words, it can determine the amount of effort a student is willing to put in by displaying what the requirements are to earn the badge.

\section{Incorporate a learning trajectory}

The practice of charting a student's learning trajectory is also important as it allows students to visualize their performance [49] and either adjust existing or set new goals for themselves. Indeed, [52] mentions that mapping the "learning trajectory" is one key design principle that they have implemented and was proposed in [61], which documented key "design principles".

One common method with which this can be achieved is through offering a learning management system, such as those provided by "Moodle, Blackboard and Canvas" [61] or OpenLearn [50], and implemented by Borders College [56], KU Leuven [37] and the Australian National University [57]. These management systems give students a general overview of progress, and provide relevant information about available courses, deadlines and timetables.

\section{Create a feedback loop to improve user experience}

The process of creating a badge has been called "a one-off operation" [29]. However, it has been argued that with regards to Open Badges, "systems are living things, and your badge system needs to be flexible" [60]. In order to continuously improve such a system, [59] posit that: "research plays a vital role in the success of your badge system". It has been further added that by "taking users' feedback into account, new elements ... can be introduced" [9].

While the analyzed pilot projects are inherently geared towards receiving feedback, it can be derived that creating a mechanism that allows for continuous feedback to be given to users could lead to an enhanced user experience overall.

In contrast to the steps required for conceptualization, the aforementioned design and implementation considerations must be addressed based on the requirements of individual institutions, on a case-by-case basis. This is largely due to the varying needs, goals and resources of issuing institutions and may therefore result in sequential or simultaneous implementation. Based on extensive analysis of current pilot projects and case studies in the academic literature, however, it is critical that each of the steps is considered in order to ensure that the expectations of badge takers are met. 


\section{CONCLUSION AND FUTURE WORK}

This paper has highlighted the motivation behind Open Badges, their benefits and limitations, how they fit into the current landscape of higher education, and summarized the underlying technological components. Finally, it has systematically analyzed case studies, pilot projects and previous frameworks in order to most accurately determine a best-practice framework for educational institutions.

The proposed framework for an Open Badge system can be separated into two distinct phases: conceptualization, and designing and implementing the system. While previous attempts have been made at a prescriptive framework, the proposed framework takes a purely institutional perspective. In addition, it provides reasoned justification for each design and conceptual principle, which is firmly rooted in the current literature. The main contribution of this paper, therefore, lies in its ability to succinctly summarize the industry best-practice while still providing a generalizable framework that can be employed by educational institutions around the world. The presence of the main findings in the form of figures and tables also allows institutions to visualize the entire process.

However, Open Badges themselves do not present a perfect solution to the growing demands on educational institutions. Institutions interested in issuing badges should be aware of the trade-off between utilizing an Open Badge system, the possibility of 'motivation displacement', and the presence of privacy concerns and institutional inertia -- amongst other factors. Moreover, the Open Badge project is continually evolving. Even if one accepts that critical mass is close to being achieved, updating and maintaining an effective Open Badge system may require significant on-going commitments of time and investment. Despite this, Open Badges present a useful way for institutions to measure and recognise skills in a way that scales well, may provide a new revenue stream, and has the ability to motivate students by providing continuous feedback. Indeed, Open Badges could go some way in alleviating the pressures educational institutions are facing and gradually become the de facto standard for institutions seeking to measure and accredit skills online.

Despite a significant increase in the amount of relevant literature, research into the effectiveness of Open Badges and more specifically, how to effectively implement such a system in educational institutions, is in its infancy. This is in part due to the notion that the Open Badge ecosystem is strongly defined by its open-source roots. Indeed, [16] argue that the "OB's initiative was largely associated with isolated efforts of individual organizations, and there was no systematic approach". Indeed, these "multifaceted educational practices" stem from "complex quagmire of social, cultural and technical factors" [31].

Future work will therefore have to bear these factors in mind when attempting to address several gaps in the technology and theoretical issues that are inherent to online education in general, as well as more specific limitations relating to Open Badges directly. More specifically, future work will have to address issues revolving around; financial viability of an OB system at scale, how to provide badges for 'soft' skills, how to allow students to create their own badges yet retain credibility, how to accurately identify employers' perception of badges and determine whether or not the introduction of Open Badges has a significantly positive effect on motivation for students overall.

Indeed, future work could use the provided framework in order to implement an Open Badge solution in practice. In doing so, it could address its limitations and identify interconnected stages during the conceptualization, designing and implementation of such a system. This could be complimented by in-depth interviews of the relevant stakeholders in order to determine further improvements.

\section{REFERENCES}

[1] I. Glover, "Open badges: a visual method of recognising achievement and increasing learner motivation," vol. 2(1), 2013.

[2] Mozilla Foundation, "Open Badges," Retrieved from http://openbadges.org/, 2015

[3] K. Xie, “Will Technology kills universities?,” Retrieved from http://time.com/3747816/education-chalkboard-chatroom/

[4] M. Poyiadgi, "Accreditation will be central to the success of Moocs," Retrieved from http://www.ft.com/cms/s/2/6c6f2ffe-a52f-11e3-898800144feab7de.html

[5] V. Devedzic, and J. Jovanovic, "Developing open badges: a comprehensive approach", Educational Technology Research and Development, vol 63, pp. 603-620.

[6] A. Hole, "Open badges: exploring the potential and practicalities of a new way of recognising skills in higher education", Journal of Learning Development in Higher Education.

[7] University of of Michigan, "Open michigan learning corps," Retrieved from http://open.umich.edu/connect/projects/badges

[8] H. Poldoja, and M. Laanpere, "Exploring the potential of open badges in blog-based university courses", New Horizons in Web Based Learning, vol. 8699, pp. 172-178.

[9] C. Santos, L. Pedro, S. Almeida, and M. Aresta, "Decentralized badges in educational contexts: the integration of open badges in sapo campus", Retrieved from

http://www.openeducationeuropa.eu/sites/default/files/asset/Fromfield_35_4.pdf

[10] S. L. Grant, "What counts as learning: open digital badges for new opportunities, ” Retrieved from http://dmlhub.net/publications/whatcounts-learning/.

[11] R. Baraniuk, "Visiones de telefonica", Retrieved from http://www.visionesdetelefonica.cl/wp-content/uploads/2012/10/05Richard-Baraniuk-Open-education.pdf.

[12] C. Clarke, “Live q\&a: online learning in 2020," Retrieved from http://blogs.ft.com/mba-blog/liveqa/2015-01-15/

[13] L. Yuan, and S. Powell, "Moocs and open education: implications for higher education," JISC CETIS. Retrieved from: www.publications.cetis.ac.uk/wp-content/uploads/2013/03/MOOCsandOpen-Education.pdf

[14] S. Cross, D. Whitelock, and R. Galley, "The use, role and reception of open badges as a method for formative and summative reward in two massive open online courses", International Journal of e-Assessment, vol 4(1). 
[15] V. Devedzic, J. Jovanovic, B. Tomic, Z. Sevarac, N. Milikic, S. Dimitrijevic, and D. Duric, "Grading soft skills with open badges," OBIE, March 2015

[16] J. Jovanovic, and V. Devedzic, "Open badges: novel means to motivate, scaffold and recognize learning", Technology, Knowledge and Learning, vol 20(1), pp. 115-122.

[17] University of Sussex, "Technology enhanced learning at sussex: open badges," Retrieved from http://www.sussex.ac.uk/tel/help/badges

[18] G. Christensen, B. Alcorn, E. Emanuel, "Harvard business review: moocs won't replace business schools - they'll diversify them," Retrieved from https://hbr.org/2014/06/moocs-wont-replace-businessschools-theyll-diversify-them/

[19] B. Bixler, "Digital badges: a conversation on the teaching and learning implications for higher education," unpublished. Retrieved from http://www.personal.psu.edu/bxb11/Resume/CHEPProposal.pdf

[20] F. Sullivan, "New and alternative assessments, digital badges and civics an overview of emerging themese and promising directions," Retrieved from http://www.civicyouth.org/wpcontent/uploads/2013/03/WP 77 Sullivan Final.pdf.

[21] E. Goligoski, "Motivating the learner: mozilla's open badges program," Access to Knowledge, vol. 4(1).

[22] M. Olneck, "Whom will digital badges empower? Sociological perspectives on digital badges," Open Badges in Education Workshop, Poughkeepsie, New York, USA.

[23] S. Deterding, "Situated motivational affordances of game elements: a conceptual model," Proceedings of the ACM CHI 2011, NY, pp. 34-37.

[24] I. Glover, and F. Latif, "Investigating perception and potential of open badges in formal higher education," World Conference on Educational Multimedia, Hypermedia and Telecommunications, Viriginia, USA.

[25] S. Briggs, "Open colleges: out with the degree, in with the badge," Retrieved from http://www.opencolleges.edu.au/informed/features/badges-in-education/.

[26] D. Randall, J. Harrison, and R. West, "Giving credit where credit is due: designing open badges for a technology integration course," TechTrends, vol. 57(6), pp. 88-95.

[27] K. Carey, "Show me your badge," Retrieved from http://www.nytimes.com/2012/11/04/education/edlife/show-me-yourbadge.html

[28] Acclaim, "Open badges for higher education," Retrieved from https://www.pearsoned.com/wp-content/uploads/Open-Badges-forHigher-Education.pdf.

[29] M. Guzman, "The future of credentials: will degrees and resumes make room for the badge?," Retrieved from http://blogs.seattletimes.com/monica-guzman/2013/04/27/the-future-ofcredentials-will-degrees-and-resumes-make-room-for-the-badge/.

[30] M. Myllymaki, and I. Hakala, "Open badges in higher education,". In L. Chova, A. Martínez, \& I. Torres (Eds.), EDULEARN14 Proceedings. 6th International Conference on Education and New Learning Technologies (pp. 2027-2034). IATED Academy. Retrieved from http://library.iated.org/publications/EDULEARN14

[31] J. Ahn, A. Pellicone, and B.S. Butler, "Open badges for education: what are the implications at the intersection of open systems and badging?," Research in Learning Technology, vol. 22, pp. 1-13.

[32] B. Meinke, "Open badges: want to make your own badges by hand? Here's how," [Web log post]. Retrieved from https://billymeinke.wordpress.com/2012/05/24/open-badges-want-tomake-your-own-badges-by-hand-heres-how/.

[33] Mozilla, "Badges, " Retrieved from https://wiki.mozilla.org/Badges.

[34] D. Waller, "Open badges: portable rewards for learner achievements," Retrieved from http://obawareness.myknowledgemap.com/MKM_open-badges_portablerewards-for-learner-achievements.pdf

[35] D. Belshaw, "Getting up to speed on the technical side of \#open badges," [Web log post]. Retrieved from http://dougbelshaw.com/blog/2012/07/02/getting-up-to-speed-on-thetechnical-side-of-openbadges/.
[36] Badge Alliance, "Open Badges Infrastructure," Retrieved from https://www.badgealliance.org/open-badges-infrastructure/open-badgesinfrastructure-working-group/.

[37] S. Charleer, J.L. Santos, J. Klerkx, and E. Duval, "Improving teacher awareness through activity, badge and content visualizations," In International Conference on Web-based Learning, Tallinn, Estonia, Retrieved from http://link.springer.com/chapter/10.1007\%2F978-3-31913296-9 16

[38] Open Badges Organization, "Implementation FAQ,". Retrieved from http://openbadges.org/legal_faq/.

[39] M.G. Moore, "Independent learning, moocs, and the open badges infrastructure," American Journal of Distance Learning, vol. 27(2), pp.75-76.

[40] J. Ferriman, "Credly and Open Badges Integration with BadgeOS!," Retrieved from http://www.learndash.com/credly-and-openbadgesintegration-with-badgeos/

[41] Mozilla, "Badges/infrastructure-tech-docs," Retrieved from https://wiki.mozilla.org/Badges/infrastructure-tech-docs.

[42] D. Gibson, N. Ostashewski, K. Flintoff, S. Grant, and E. Knight, "Digital badges in education," Education and Information Technologies, vol. 20(2), pp. 403-410.

[43] P. Baxter, and S. Jack, "Qualitative case study methodology: study design and implementation for novice researchers," The Qualitative Report, vol. 13(4), pp. 544-559.

[44] A. Halavais, "A genealogy of badges," Information, Communication \& Society, vol 15(3), pp. 353-373.

[45] G. Christensen, A. Steinmetz, B. Alcorn, A. Bennett, D. Woods, and E. Emanuel, "The mooc phenomenon: who takes massive open online courses and why?," Manuscript submitted for publication, Department of Medical Ethics and Health Policy, University of Pennsylvania. Retrieved http://papers.ssrn.com/sol3/papers.cfm?abstract id=2350964

[46] R. Ferguson, "Learning analytics: drivers, developments and challenges," International Journal of Technology Enhanced Learning, vol. 4(5), pp. 304-317.

[47] B.J. Fishman, and S. Deterding, "Beyond badges \& points: gameful assessment systems for engagement in formal education," Retrieved from

http:/teach.its.uiowa.edu/files/teach.its.uiowa.edu/files/cft GBL GLS Beyond_Badges.pdf

[48] G. A. Lancaster, S. Dodd, and P.R. Williamson, "Design and analysis of pilot studies: recommendations for good practice," Journal of Evaluation in Clinical Practice, vol. 10(2), pp. 307-312.

[49] S. Cucchiara, A. Giglio, D. Persico, and J.E. Raffaghelli, "Supporting self-regulated learning through digital badges: a case study," New Horizons in Web Based Learning, vol. 8699, pp. 133-142.

[50] P. Law, L. Perryman, and A. Law, "Badging and employability at the open university," In European Distance and E-Learning Network (EDEN) 2014 Annual Conference, Zagreb, Retrieved from http://oro.open.ac.uk/40480/1/EDENsubmission final.pdf.

[51] E. Pogorelc, "Online assessment through peers," Retrieved from http://conference.oeconsortium.org/2014/wpcontent/uploads/2014/02/Paper_33-Assessment.pdf.

[52] C. Gamrat, and H.T. Zimmerman, "An online badging system supporting educators' STEM learning," In Workshop in Open Badges in Education, New York, USA, Retrieved from http://sites.psu.edu/heatherzimmerman/wpcontent/uploads/sites/3832/2015/03/Gamrat_Zimmerman_2015_OBIE_ Workshop Long Paper.pdf.

[53] W. O'Bryne, K. Schenke, J. Willis III, and D. Hickey, "Digital badges: recognizing, assessing, and motivating learners in and out of school contexts," Journal of Adolescent \& Adult Literacy, vol. 58(6), pp. 451454.

[54] K. Smith, K. Meisner, L. Shade, T. Sherpherd, and D. Belshaw, "Codesigning open badges for privacy education with canadian youth: a project report," Retrieved from http://hivetoronto.org/wpcontent/uploads/2014/09/CoDesigningBadgesFinalReport30March2015.pdf 
[55] B.S. Barker, "Digital badges in informal learning environments," In The Eighth International Conference on Internet and Web Applications and Services, Rome, Italy, Retrieved from www.thinkmind.org/download.php\%3Farticleid\%3Diciw_2013_11_10 $20013+\& \mathrm{~cd}=1 \& \mathrm{hl}=\mathrm{en} \& \mathrm{ct}=\mathrm{clnk} \& \mathrm{gl}=\mathrm{uk}$.

[56] S. Scott, "RSC scotland: open badge adventure at borders college," Retrieved from http://www.rsc-scotland.org/?p=2454.

[57] I. Mewburn, K. Freund, and E. Rutherford, "Badge trouble: piloting open badges at the australian national university," In B. Hegarty, J. McDonald, \& S.-K. Loke (Eds.), Rhetoric and Reality: Critical perspectives on educational technology. Proceedings Ascilite Dunedin 2014 (pp. 643-648).

[58] S.P. Boyle, S. Burke, and P. Collins, "Exploring the feasibility of awarding open badges to jorum users," In OER15 Conference, Cardiff, Wales, $\quad$ Retrieved from http://www.researchgate.net/publication/271703147_Exploring the Fea sibility of Awarding Open Badges to Jorum Users.

[59] C. Casili et a., "A collaboratively drafted campus policy framework for open badges," Retrieved from
http://www.academia.edu/8830797/A_collaboratively_drafted_campus policy framework for open badges.

[60] C. Casili, "Badge system design: standardization, formalization \& uniquess," Retrieved

https://carlacasilli.wordpress.com/2012/04/27/badge-system-designstandardization-formalization-uniqueness/

[61] D. Hickey, N. Otto, R. Itow, K. Schenke, C. Tran, and C. Chow, "Badge design principles documentation project: interim report january 2014 update," Retrieved from http://dpdproject.info/files/2014/05/DPDinterim-report-v4-january.pdf

[62] R. Davies, D. Randall, R. West, "Using open badges to certify practicing evaluators," American Jounral of Evaluation, pp. 1-13.

[63] The University of British Columbia, "Level 2 on Fundamentals of Design [Image]," Retrieved from http://badges.open.edu.ubc.ca/learn/introduction

[64] Mozilla, "Mozilla Open Badge Infrastructure [Image]," Retrieved from https://wiki.mozilla.org/Badges/Onboarding-Earner. 